\title{
Preparation For The MRCS In Surgery
}

\author{
MB Green
}

\section{Introduction}

The examination of Membership of the Royal College of Surgeons (MRCS) serves as the exit examination for aspiring surgeons completing their Basic Surgical Training (BST). It is administered by the four surgical Royal Colleges (Edinburgh, England, Ireland and Glasgow) and is a prerequisite for advancement to the Specialist Registrar grade in any surgical speciality. It has replaced the old Fellowship (FRCS) examination, which is now taken as an exit examination at the end of Higher Surgical Training. Basic surgical training in general, and the MRCS examination in particular are about to undergo a period of significant change and upheaval, as the Royal Colleges seek to make BST more relevant to surgical practice in the current Health Service.

\section{The current MRCS}

This is included for the sake of completeness as anyone embarking on basic surgical training after January 2004 will automatically be enrolled into the new intercollegiate examination system (vide infra). Currently, the examination is divided into two written papers with a combination of multiple choice (MCQ) and extended matching (EMQ) questions. The first paper concentrates on 'Core' knowledge and the second paper on 'Systems'. After successful completion of the written papers, candidates must then pass a viva voce and then a clinical examination. Each Royal College writes its own examinations and there is only limited reciprocity between the various parts of the exam from different colleges.

\section{MRCS from January 2004}

From this date, the MRCS will adopt an intercollegiate format, similar to MRCP, with all new trainees enrolled within the new system. Trainees midway through the 'old' system will be allowed to complete their membership on the original format.

Broadly, the examination will consist of three parts. Part 1 is an MCQ paper testing Applied Basic Sciences, Part 2 is an EMQ paper to test clinical problem solving and Part 3 is the Final Assessment consisting of both a viva voce and a clinical examination. All 4 Colleges will present identical written papers to candidates across the country (and at overseas centres) at simultaneous sittings, currently planned for January, April and
September. Whilst the timing of Final Assessment examinations is currently undecided, it is envisaged that the new arrangements will continue to allow two sittings at each college every year.

\section{Organisation of the \\ Examination}

Although the format of surgical examinations has changed enormously throughout the last decade, one myth still remains. Contrary to popular belief, examiners do not have a quota of passes, rather a pass mark is defined prior to examination, and all candidates above that level are successful.

\section{Part 1}

This paper will consist of Multiple Choice questions testing Applied Basic Sciences. The paper is not negatively marked and is answered on a computer-read form; all scores within 5 of the pass mark are checked manually to eliminate computer error.

\section{Part 2}

This paper will consist of Extended Matching Questions testing clinical problem solving. Questions consist of a theme, a number of options and a variable number of clinical situations. For each situation the single most likely option should be chosen (Box 1). Again there is positive marking and scrutiny of borderline scores.

\section{Part 3}

This will consist of a viva voce examination and a separate clinical assessment, and is likely to follow the formats currently employed by the Colleges. The viva covers the whole of the surgical syllabus and is divided into broad categories including Applied Anatomy, Physiology and Pathology, Operative Surgery, Principles of Surgery and Critical Care. The candidate is questioned for 10 minutes in each category whilst a second examiner acts as observer. At present, only the Royal College of Surgeons of England examines communication skills separately, and this test using actors as patients is appended to the viva voce examination day. The precise format and duration of individual vivas currently varies between colleges and an 'intercollegiate' style has yet to be announced. Similarly, the arrangements for the new Clinical Assessment are unknown. Presently the two Scottish 
Box 1. An example of a typical extended matching question.

\begin{tabular}{|c|c|c|}
\hline \multicolumn{3}{|c|}{ Options: } \\
\hline \multirow{5}{*}{ Swollen, painful joints } & a & Osteoarthritis \\
\hline & & Gout \\
\hline & & Rheumatoid arthritis \\
\hline & & Tuberculous arthritis \\
\hline & $\mathrm{e}$ & Neuropathic joint disease \\
\hline \multicolumn{3}{|c|}{$\begin{array}{l}\text { For each of the patients described below, select the single most likely diagnosis from the options listed above. } \\
\text { Each option may be used once, more than once or not at all. }\end{array}$} \\
\hline \multicolumn{3}{|c|}{$\begin{array}{l}\text { 61. A 35- year old woman progressively develops pain, swelling and stiffness of her hands. On examination, two } \\
\text { years after the onset of her joint complaints, she is found to have swelling and tenderness in relation to the } \\
\text { metacarpo-phalangeal joints. X-rays of the affected joints show diminution of joint space, as well as } \\
\text { osteoporosis and marginal erosions of the articulating bones. }\end{array}$} \\
\hline \multicolumn{3}{|c|}{$\begin{array}{l}\text { 62. A 60- year old woman complains of pain and swelling of gradual onset in both her knees over a period of } \\
\text { two years. On examination there is evidence of excess synovial fluid and synovial thickening in both knee joints } \\
\text { and local tenderness. Standing X-rays of her knees show diminution of joint space, sclerosis and cysts in the } \\
\text { adjacent bones. Osteophytes are also seen at the articular margins. }\end{array}$} \\
\hline
\end{tabular}

Colleges use a 40 minute ward round setting for the clinical examination, whereas England and Ireland use themed bays, broadly divided into vascular, orthopaedics and neurology, trunk and "lumps and bumps" cases. Candidates are usually asked to see a number of cases during the 15 minutes in each bay.

No matter how candidates are examined in the final assessment, it is pertinent to point out that what the examiners are looking for are the qualities they would expect their registrar to demonstrate, namely a candidate who is safe, courteous and kind with patients, reliable and has a sound basic knowledge. Poor patient skills, dishonesty or exaggeration and unsafe practice are a guarantee of failure.

\section{Eligibility for the Examinations}

Changes in the organisation of the MRCS examination are running concurrently with a major overhaul of the whole of basic surgical training, which will result in the granting of a Certificate of Completion of Basic Surgical Training (CCBST) to parallel the recent changes in Higher Surgical Training. The details of how CCBST is to be obtained and the exact relevance to continuing surgical

Table 1. Suitable posts for Basic Surgical Training*

\begin{tabular}{|c|c|}
\hline General Surgery or one of its sub-specialities & Trauma \& Orthopaedics or one of its subspecialties \\
\hline Accident \& Emergency Medicine & Cardiothoracic Surgery \\
\hline Neurosurgery & Oral \& Maxillofacial Surgery \\
\hline Otorhinolaryngology & Paediatric Surgery \\
\hline Plastic Surgery & Urology \\
\hline \multicolumn{2}{|c|}{$\begin{array}{l}\text { Posts in the following specialities are also considered suitable if they hold approval by the } \\
\text { appropriate Royal College }\end{array}$} \\
\hline Gynaecology & Ophthalmology \\
\hline
\end{tabular}

* The 24 months BST may comprise 4 six-month posts, 6 four-month posts or a combination of both. training have not yet been published, but it is intended that CCBST will certify that a candidate has obtained MRCS, passed all mandatory training courses and successfully completed 24 months in approved training posts. It is possible that further requirements may be announced in due course. The introduction of training schemes under the CCBST auspices will render the current requirement for a certain period of BST to have been completed prior to sitting Part 3 obsolete. Candidates will only need to have embarked upon approved BST in order to attempt any part of the examination, although Parts $1 \& 2$ must still be passed before proceeding to Part 3. Candidates will have a total of 42 months to complete the examination from the date of their first attempt at part 2.

The period of compulsory basic surgical training necessary for CCBST is 24 months spent in approved posts in a range of surgical specialities (Table 1). The timetable of these approved posts must include periods for operating, outpatients, ward work, administration, personal study, teaching (including audit and interdepartmental meetings) and any on-call commitment. Provision is also required for Study Leave. 
Table 2. A summary of useful courses during basic surgical training.

\begin{tabular}{|c|c|c|}
\hline Course & Provider / Cost & Aims \\
\hline ATLS & $\begin{array}{l}\text { Under auspices of } \\
\text { RCSEng at centres } \\
\text { around the country - } \\
£ 625\end{array}$ & $\begin{array}{l}3 \text { days. Provides a system for safe initial evaluation and treatment } \\
\text { of trauma patients. Mixture of lectures, skill stations and } \\
\text { moulage exercises. }\end{array}$ \\
\hline $\begin{array}{l}\text { Care of the } \\
\text { Critically Ill } \\
\text { Surgical Patient } \\
\text { (CCrISP) }\end{array}$ & RCSEng - £750 & $\begin{array}{l}21 / 2 \text { days aimed at providing experienced basic surgical trainees } \\
\text { with the skills to deal with seriously ill patients. RCSEd host a } \\
\text { similarly designed course - The Early Trauma and Critical Care } \\
\text { Course. }\end{array}$ \\
\hline Distance Learning & $\begin{array}{l}\text { RCSEng- STEP - } \\
£ 1370 \\
\text { RCSEd - SELECT - } \\
£ 1250 \\
\text { RCSI - BeST }\end{array}$ & $\begin{array}{l}\text { STEP (Surgeons in Training Education Programme), SELECT } \\
\text { (Surgical Education Linking effective study, Clinical practice } \\
\text { and Training) and BeST (electronic Basic Surgical Training) all } \\
\text { aim to provide guidance on study throughout the entire duration } \\
\text { of BST rather than cramming for the exams. }\end{array}$ \\
\hline Exam Preparation & $\begin{array}{l}\text { RCSEng }-£ 1400-1550 \\
\text { St Thomas's } \\
\text { Sheffield } \\
\text { Pastest }\end{array}$ & $\begin{array}{l}\text { A growing number of training centres now offer revision courses } \\
\text { for specific parts of the MRCS, notably the clinical and viva } \\
\text { sections. The London course is a } 3 \text { week viva revision course. }\end{array}$ \\
\hline
\end{tabular}

\section{Relevant courses}

Basic surgical training courses can be generally divided into two groups, those that benefit ones day to day practice and skills, such as Basic Surgical Skills (BSS), Advanced Trauma Life Support (ATLS) or a surgical critical care course, and secondly courses that help to prepare for taking specific parts of the MRCS examination and are aimed solely at obtaining an examination pass.

The Basic Surgical Skills Course is aimed at those commencing surgical training and is designed to be taken as early as possible during BST. Successful completion of the course is a mandatory requirement for advancement to Part 3 of the MRCS. It is a two day course concentrating on the acquisition of practical skills and has a high instructor to student ratio $(1: 2)$. It is divided into three sections to teach general surgical skills (including instrument handling, suturing and basic anastomotic techniques), orthopaedic skills (including fracture reduction and application of plaster casts) and a shorter section concentrating on basic laparoscopic skills. It is run at multiple centres around the country, in addition to the Royal Colleges and currently costs approximately $£ 500$.

All other basic surgical training courses are voluntary and they are summarised in Table 2.

\section{General preparation}

The key to success in all examinations is adequate preparation and the MRCS is no exception. The acquisition of the requisite knowledge takes time and this implies that preparations should begin well in advance of need, rather than cramming for the examination in true undergraduate style. Remember that this examination will determine the course of the rest of your professional career - and you have to pay for the privilege too, so it is worth treating it with respect.

The knowledge one needs for MRCS can be gained from many sources, some of which may not obviously spring to mind. Find a range of basic text books that suit the manner in which you feel you learn best, as there is nothing worse than trying to summon the enthusiasm to plough through a weighty tome whose style you do not like. Table 3 lists some of the titles that are helpful but remember that this is only a selection of the books on offer and that their respective styles may not be to everyone's taste.

In the early stages of preparation, enrolment in one of the distance learning courses mentioned earlier should be beneficial. Not only does it give the candidate some idea of the breadth of the syllabus but it can also act as a stimulus to revise, given that it is generally easier to set yourself a couple of pages of the STEP course per night rather than embarking on chapter after chapter of textbook reading.

\section{Specific preparation}

As Part 1 of the MRCS is MCQ based, a style of question that most candidate are familiar with from Medical School, the format of the examination should be straightforward, although it is worth paying specific attention to the instructions given with each set of questions as subtle variations may trip up the unwary. The best way to ensure success in an MCQ paper is to answer lots of them as practice papers beforehand. The more MCQs one answers, the better one's overall performance will become. There are numerous books of MCQs available, broken down by topic, system or as practice papers. In addition several internet sites also provide online practice, often with automatic marking and scoring facilities. The secret is 
Table 3. Books For Revision.

\begin{tabular}{|c|c|}
\hline & Comments \\
\hline $\begin{array}{l}\text { Kingsnorth A Majid A. Principles of surgical practice. } \\
\text { London: Greenwich Medical Media, } 2001 .\end{array}$ & $\begin{array}{l}\text { Excellent overview of principles underlying surgical } \\
\text { practice. }\end{array}$ \\
\hline $\begin{array}{l}\text { Kirk R M, Winslet M C. Essential General Surgical } \\
\text { Operations for the MRCS/AFRCS. Churchill } \\
\text { Livingston } 2001 .\end{array}$ & $\begin{array}{l}\text { Well set out book covering all the operations you } \\
\text { will be expected to know at the exam. An } \\
\text { abridged version of a standard HST text. }\end{array}$ \\
\hline $\begin{array}{l}\text { Thomas W E G. Preparation and Revision for } \\
\text { the MRCS and AFRCS Examination. } \\
\text { Churchill Livingston } 1998 .\end{array}$ & $\begin{array}{l}\text { Good overview with some useful tips. In need of } \\
\text { revision now that format of exams has changed. }\end{array}$ \\
\hline $\begin{array}{l}\text { Chan C. Hart A. Viva: Practice for MRCS. } \\
\text { Pastest } 2001 .\end{array}$ & $\begin{array}{l}\text { Useful as a guide for setting questions for yourself, or } \\
\text { use in a group. Some inaccuracies. }\end{array}$ \\
\hline $\begin{array}{l}\text { Servant C J. Purkiss C F. Examination Schemes } \\
\text { in General Surgery and Orthopaedics Greenwich } \\
\text { Medical Media } 1997 .\end{array}$ & Good as an aide-memoir. \\
\hline $\begin{array}{l}\text { Morris-Stiff G. Bowrey D J. Puntis M A. } \\
\text { Rees B I. Shandall A A. Clinical Cases for the } \\
\text { MRCS and AFRCS. Arnold } 1998 \text {. }\end{array}$ & Good for spot diagnoses only. \\
\hline $\begin{array}{l}\text { Raftery A T. Applied Basic Science for Basic } \\
\text { Surgical Training. Churchill Livingstone } 2000 .\end{array}$ & $\begin{array}{l}\text { Almost essential. Has all the information necessary to } \\
\text { pass the viva. Some chapters are hard work to read, but } \\
\text { definitely worth the effort. }\end{array}$ \\
\hline $\begin{array}{l}\text { Lowe D. General Pathology Vivas. Greenwich } \\
\text { Medical Media } 2001 .\end{array}$ & $\begin{array}{l}\text { Contains most of the topics examiners will ask about } \\
\text { pathology! Given as part of the RCSEng viva course. }\end{array}$ \\
\hline $\begin{array}{l}\text { Ellis H. Clinical Anatomy 10th Ed. } \\
\text { Blackwell Publishing. } 2002 .\end{array}$ & $\begin{array}{l}\text { THE book to know if you want to pass the anatomy } \\
\text { viva. Includes information on clinical relevance of facts } \\
\text { to help prevent "dryness". }\end{array}$ \\
\hline $\begin{array}{l}\text { Parchment-Smith C. Surgical Short Cases for } \\
\text { the MRCS Clinical Examination. Pastest. } 2002 .\end{array}$ & $\begin{array}{l}\text { Brilliant. Examination schemes, a script for } \\
\text { presentations and all the key facts about conditions you } \\
\text { will meet. Also has detailed survey of previous candidate } \\
\text { experience to give a guide to frequency of case } \\
\text { appearance. }\end{array}$ \\
\hline
\end{tabular}

\section{to practice this style of questions}

Part 2 of the new examination is based around extended matching questions. This style of question (Box1) may not be as familiar as standard MCQs and so further practice with this format is recommended. As EMQs become more popular with examiners, the number of books of sample questions grows. The comments above are as equally applicable to EMQs as they are to MCQs.

The viva voce examination is still the section that provokes most palpitations for candidates, partly because it is a format that most are not well practiced at and partly because there is a sense of the unknown as the examiners are at liberty to interrogate you on any part of the surgical syllabus. Preparation for this section of the examination is two-fold, concentrating on both the knowledge and practice questions in a viva setting.

In a typical viva, a rather innocuous general opening question such as "What is MRSA?" serves as a lead-in to more in depth probing, often picking up on an element of the candidate's answer. Practice at answering viva questions in the correct manner is essential; for example when asked about the complications of a given procedure, rather than launching into a random list, one should start with a stock phrase, such as

'... the complications of this procedure can be divided into general and specific. The specific complications may be immediate, early or delayed. Immediate complications include..... This approach not only gives the examiner the impression that the candidate is organised and methodical but allows the examinee valuable time to come up with the specifics of the answer!

Undoubtedly, the only way to adequately prepare for the viva examination is to be questioned by friends, contemporaries and seniors at every possible opportunity - the more formal the setting the better as it helps prepare one for the gut-wrenching nervousness that usually pervades the Viva hall. No opportunity to be interrogated should be overlooked: operations give your boss the scope for questions on anatomy, operative surgery, principles of surgery and pathology, whilst the anaesthetist at the head of the table spends the working day practicing applied physiology and potentially critical care and will doubtless relish the chance to put a young surgeon through their paces. Books of viva questions are also available so that this purgatory can be continued in the comfort of your own home!

Candidates must present their Surgical Logbook at the viva. It must be up to date and you will be expected to be able to answer questions on any procedure you claim to have seen or performed. Try and avoid the 
use of eponymous operation titles when completing the log book as, some examiners will view this as an invitation to question you on the minutiae of performing a procedure the same way as the inventor!

The clinical examination also requires a sound knowledge base, (which by this stage should be well ingrained), but is primarily an evaluation of practical skills and clinical acumen. It is important that the candidate not only performs a thorough examination, but, is seen to perform a thorough examination. Unsurprisingly, the key here is yet again to practice your examination skills at every opportunity, and to be critiqued by your elders and betters. Half the battle in the clinical assessment is to look as if you perform the required examination on a daily basis; even if you don't find the abnormality, you will still score well if you examine in a manner that suggests you might find the pathology!

\section{Summary}

The MRCS is an examination in a state of flux at the moment and the precise requirements of the forthcoming intercollegiate examinations are still awaited, but it is expected that many of its features will be directly translated from the current arrangements. The keys to success can perhaps be summarised as follows: start work well in advance of the examinations, take every opportunity to practice your skills and look upon questioning by your seniors as a chance to practice rather than an imposition.
Finding the textbooks that suit your style of learning early on and practising sample questions as often as possible will pay dividends.

\section{Useful Addresses and Websites}

Royal College of Surgeons, 35-43 Lincoln's

Inn Fields, London, WC2A 3PE

Tel: 02074053474 www.rcseng.ac.uk .

Royal College of Surgeons of Edinburgh, Nicolson Street, Edinburgh, EH8 9DW

Tel: 01315271600 www.rcsed.ac.uk.

Royal College of Physicians and Surgeons of Glasgow, 232-242 St Vincent Street, Glasgow,G2 5RJ Tel: 01412216072 www.rcpsglas.ac.uk .

Royal College of Surgeons in Ireland, 123

St Stephens Green, Dublin 2, Eire Tel: +3531 4022100 www.rsci.ie.

www.surgical-tutor.org.uk : excellent website with comprehensive revision notes available to view or buy. It also has revision tips and reports of exam topics and experiences from recent candidates.

www.mcqs.com : Subscription website with MCQs galore.

www.pastest.co.uk : Information on courses, books etc provided by Pastest. Has some MCQs for those who subscribe. 